\title{
Diagnostic Features and Management Options for Duodenal Neuroendocrine Neoplasms: A retrospective, Multi-Centre Study
}

Dalvinder Mandair ( $\boldsymbol{\nabla}$ dalvinder.mandair@nhs.net)

Neuroendocrine Tumour Unit, ENETS Centre of Excellence, Royal Free Hospital, London

\section{Lukasz Kamieniarz}

University College Medical School, London

\section{Michail Pizanias}

Neuroendocrine Tumour Unit, ENETS Centre of Excellence, Institute of Liver Studies, Kings College Hospital, London

\section{Martin Weickert}

The ARDEN NET Centre, ENETS CoE, University Hospitals Coventry and Warwickshire (UHCW) NHS Trust, Coventry, CV2 2DX, UK; and Centre of Applied Biological \& Exercise Sciences (ABES), Faculty of

\section{Akshay Narayan}

University College Medical School, London

\section{Luke Furtado O'Mahony}

University College Medical School, London

\section{Martyn Caplin}

Neuroendocrine Tumour Unit, ENETS Centre of Excellence, Royal Free Hospital, London John Ramage

Neuroendocrine Tumour Unit, ENETS Centre of Excellence, Institute of Liver Studies, Kings College Hospital, London

\section{Andreas Prachalias}

Department of Hepatobiliary Surgery, Institute of Liver Studies, Kings College Hospital

\section{Rajaventhan Srirajaskanthan}

Neuroendocrine Tumour Unit, ENETS Centre of Excellence, Institute of Liver Studies, Kings College Hospital, London

\section{Christos Toumpanakis}

Neuroendocrine Tumour Unit, ENETS Centre of Excellence, Royal Free Hospital, London

\section{Research Article}

Keywords: duodenal neuroendocrine tumours, carcinoid, Ki67 
Posted Date: July 19th, 2021

DOI: https://doi.org/10.21203/rs.3.rs-659053/v1

License: (c) (i) This work is licensed under a Creative Commons Attribution 4.0 International License. Read Full License 
Diagnostic features and management options for Duodenal Neuroendocrine Neoplasms: A retrospective, multi-centre study

Dalvinder Mandair ${ }^{1,}$ Lukasz Kamieniarz $^{2}$, Michail Pizanias ${ }^{3}$, Martin O Weickert ${ }^{4}$, Akshay Narayan ${ }^{2}$, Luke Furtado O'Mahony ${ }^{2}$, Martyn Caplin ${ }^{1}$, John Ramage ${ }^{3}$ ,Andreas Prachalias ${ }^{5}$, Rajaventhan Srirajaskanthan ${ }^{3}$, Christos Toumpanakis ${ }^{1}$,

${ }^{1}$ Neuroendocrine Tumour Unit, ENETS Centre of Excellence, Royal Free Hospital, London

${ }^{2}$ University College Medical School, London

${ }^{3}$ Neuroendocrine Tumour Unit, ENETS Centre of Excellence, Institute of Liver Studies, Kings College Hospital, London

${ }^{4}$ The ARDEN NET Centre, ENETS CoE, University Hospitals Coventry and Warwickshire (UHCW) NHS Trust, Coventry, CV2 2DX, UK; and Centre of Applied Biological \& Exercise Sciences (ABES), Faculty of Health \& Life Sciences, Coventry University, Coventry CV1 5FB, UK

${ }^{5}$ Department of Hepatobiliary Surgery, Institute of Liver Studies, Kings College Hospital

Short title: Management of duodenal Neuroendocrine Neoplasms

Keywords: duodenal neuroendocrine tumours, carcinoid, Ki67

Corresponding author: Dr Dalvinder Mandair, Neuroendocrine Tumour Unit, Royal Free Hospital, London, NW3 2QG, email; dalvinder.mandair@nhs.net

Conflict of Interest: The authors declare no potential conflicts of interest 
Summary

Background

Duodenal neuroendocrine neoplasms (dNENs) are rare neoplasms but their incidence is on the rise. They are classified into 5 sub-types but there remains much heterogeneity in behaviour in particular of non-functioning dNENs

\section{Aim}

To retrospectively analyse outcomes for all types of dNENs, and highlight prognostic factors associated with worse outcome

Results

$102(57 \mathrm{~m} / 45 \mathrm{f})$ patients were identified with mean age at diagnosis 62 (range 32-87) years. The majority were non-functioning tumours $87 / 102$ and median size was $10 \mathrm{~mm}$ (range $0.9-130 \mathrm{~mm}$ ). 83 patients had Stage I or II disease, of which 17 underwent endoscopic resection with $\mathrm{R} 1$ rate of $45 \%$ and complication rate $12 \% .36$ patients were kept under endoscopic surveillance. There were 11 deaths of which 4 were disease related. Age and Ki67 > 20\% were associated with worse OS in all dNENs. In non-functioning dNENs Ki67 >3\% was a predictor of lymph nodes metastases with OR $18.2(2.54-13)(p<0.005)$ in univariate analyses and liver metastases with OR $6.79(1.56-29.5)(p<0.05)$ in the multivariate analysis. Lesions $11-20 \mathrm{~mm}$ in size had OR $11.1(1.16-106)$ compared to lesions $<11 \mathrm{~mm}$ for the prediction of lymph node metastases in the multivariate analysis $(p<0.05)$. ROC analysis of size of non-functioning dNENs to predict LN metastases found $<15 \mathrm{~mm}$ had an AUROC of $0.9(0.81-0.99)$ with a sensitivity of $85 \%$ and specificity of $88 \%$. 
Conclusion

dNENs are increasing in incidence, however low grade and smaller lesions have an indolent course and the role of endoscopic resection and active surveillance needs to be reviewed. 


\section{Introduction}

Duodenal neuroendocrine neoplasms (dNENs) are rare neoplasms with a reported incidence of 0.17 per 100,000 [1]. They represent at least $2.7 \%$ of all NENs [2]. This figure is on the rise along with the incidence of all NENs which has increased from 1.09 per 100,000 in 1973 population to 6.98 in 2012 according to US based National surveillance, epidemiology and end results database (SEER). The incidence of localised disease has increased from 0.21 per 100,000 to 3.15 per 100,000 in 2012 [3].This rise in NENs detected at an early stage is likely due to the increase in endoscopy investigations being performed and more generous use of scans such as computed tomography in asymptomatic patients [4].

dNENs are classified into 5 clinical sub-types: non-functioning, functioning consisting of gastrinomas and somatostatinomas, carcinoids (serotonin-secreting), duodenal paragangliomas and poorly differentiated neuroendocrine carcinomas (NECs) $[5,6]$. Epidemiological studies from the previous decade reported the syndromic subtypes of dNENs (specifically the gastrinomas and the carcinoid tumours) as more prevalent than the non-functioning dNENs [5,7]. In the last 20 years an increasing proportion of non-functioning dNENs are found incidentally at endoscopy and are now the most prevalent sub-type [8]. The average size of the dNENs at diagnosis has been reported to be between $1.2 \mathrm{~cm}$ and $1.85 \mathrm{~cm}$ in previous studies $[5,9]$. The incidence of lymph nodes has been reported as high as 40-60\%[1], with liver metastases seen in $10-15 \%[1,5]$. The tumour histology affects the survival: patients with neuroendocrine carcinomas (NECs) have a median survival of just over a year [10]. Other previously identified significant factors in the prognosis of these neoplasms include depth of invasion, size and mitotic activity. Tumours below $<1 \mathrm{~cm}$ are rarely associated with distant metastases and local lymph node involvement is seen in less than $5 \%$ of 
patients [11]. Invasion of muscularis propria and high mitotic rate are associated with higher risk for metastatic disease [1].

The current ENETS dNENs management guidelines recommend endoscopic removal of all non-functioning dNENs $<1 \mathrm{~cm}[1]$. The incidence of complications post endoscopic resection has recently been reported as $8.6 \%(24 / 279)$ in a systematic review of 21 retrospective studies[12].The proportion of resections with tumour present at the margin (R1) has been reported as high as 40\% [13].

With a high complication rate at endoscopic resection, but also the indolent behaviour seen in many smaller lesions, there is a need for further evaluation of the outcomes of non-functioning dNENs.

The aim of this study was to retrospectively analyse the behaviour and outcomes for all types of dNENs, with an attempt to highlight prognostic factors associated with worse outcome

\section{Materials and methods}

\section{Study population}

This was multi-centre study retrospective study involving 3 ENETs Centres of Excellence, University Hospitals Coventry and Warwickshire (UHCW audit proposal number 139/2017), Kings College Hospital and the Royal Free Hospital. Patients presented between to these centres between January 2005 and December 2017. 102 patients were identified by searches of NET patient database in each centre. All patients had histological confirmation from either biopsy, endoscopic or surgical resection or from liver metastases. Ampullary NENs were not included in this 
analysis as their behaviour is more closely associated with that of pancreatic NENs. Patients with synchronous tumours in other sites were also excluded.

\section{Ethics}

This was a retrospective study observational study, there were no experiments conducted on the patients and all patients provided consent. This study was registered with the Quality Governance and clinical audit committee of the Royal Free Hospital NHS Trust and was conducted in accordance with the Declaration of Helsinki.

\section{Data analyses}

The clinico-pathological records were analysed and data collected using a predeveloped clinical record form. Size, grade, and location of each the duodenal lesion was recorded. Their clinical subtype was also recorded. Where there were multiple lesions, the largest was included in the survival analyses. Histological grade was assessed and according to the WHO guidelines 2015 for GEP-NETS. The presence of lymph node, hepatic and skeletal metastases was assessed, at the time of diagnosis and follow-up, through cross-sectional and molecular imaging (Gallium 68 DOTATATE PET scan or Octreoscan +/- FDG PET). Tumours were staged according to the ENETs TNM classification for gastroduodenal neuroendocrine neoplasms [14]. All treatments were recorded. Overall survival was defined as time of diagnosis till most recent follow-up July 2018. There were few deaths recorded in the follow-up period, therefore in the survival analysis all dNENs were included (high grade and functioning). These groups were excluded from a sub-group analysis of non-functioning well differentiated dNENs where risk factors for lymph node and liver metastases were investigated. 


\section{Statistics}

Statistical analyses was performed using Graph pad Prism version 8 and Stata version 16. Categorical variables were presented as frequencies and percentages and continuous variables as means with range. Survival was estimated using Kaplan-Meier methods and cox hazards ratios were calculated to compare differences in survival in patient groups. Logistic regression analysis was performed to determine the risk factors for the presence of lymph node or liver metastases.

\section{Results:}

\section{Patients}

There were one and hundred and two patients with complete medical records identified from 3 ENETs centres of excellence. Tumour characteristics are summarised in table 1 . There were a similar number of male and female patients with mean age at diagnosis 62 (range 32-87) years. The majority of tumours were found in D1 (75\%) and 87 were non-functioning dNENs (85\%). Most patients were found at an earlier stage, with 46 patients at Stage I and 27 at Stage II. The mean size of tumour was $16 \mathrm{~mm}$, consistent with previously reported data, with median $10 \mathrm{~mm}$ (range $1-130 \mathrm{~mm}$ ). All patients that demonstrated FDG-PET avidity in the primary or metastases had a Ki67 of more than 15\%.

\section{Treatments}


Patients with Stage I or Stage II disease that was technically resectable were managed with active surveillance in 36 cases. Endoscopic resection (ER) was performed in 17 cases with an incomplete $(R 1)$ resection rate seen $45 \%$. Two cases proceeded to surgery (12\%) after ER, due to development of perforation. Surgery was performed in a total of 30 cases. Medical therapy was used for patients who presented with Stage IV disease or those that later developed recurrence after previous surgery. The majority received first line treatment with somatostatin analogues (23 out of 25 ); the exception being those with poorly differentiated NEC, who received chemotherapy. Patients that progressed on somatostatin analogues were given either Peptide Receptor Radionuclide Therapy (PRRT) or chemotherapy and this decision was based on tumour avidity in somatostatin receptor imaging (either Gallium 68 DOTATATE PET scan or Octreoscan).

Treatment options for all patients are summarized in Table 1. Some patients received more than one treatment. There were 5 patients that required medical therapy for recurrence after previous surgery.

\section{Overall survival}

At the end of the follow-up period there had been 11 deaths with disease related mortality seen in only 4 patients (4\%) and 2 of these patients were poorly differentiated NECs. All dNENs were included in the survival analysis

Age was a significant predictor of survival in the multivariate cox hazards analysis with a HR 2.1.2 $(p<0.05)$

Functioning dNENs appeared to fare worse than non-functioning with HR 3.13 (0.8511.1) $(p=0.05)$ but this was not significant in the multivariate analysis. The summary of cox hazards univariate and multivariate is shown in table 2. 
Ki67 was a significant predictor of overall survival in the univariate analysis. A Ki67 of $20 \%$ was used as a cut-off in the survival analysis. The Kaplan-Meier curve is demonstrated in Figure 1. The median survival with patients with a ki67 of $>20 \%$ was 1.83 years, whilst that of Ki67 $<20 \%$ was not reached $(p=0.0001)$.

Size was not a significant predictor of survival in this analysis because there were too few deaths in the follow-up period. However when adjusted for disease related mortality, the 5 year survival lesion was $100 \%$ for lesions less than $1 \mathrm{~cm}$ in size.

\section{$\underline{\text { Risk factors for metastases }}$}

To identify the risk factors for lymph node and liver metastases, sub-group analysis was performed on non-functioning dNENs as this represented a more homogenous group. The univariate and multivariate logistic regression analysis is summarised in table's 3 and 4 . Ki67 was a predictor of lymph node metastases in the univariate analysis with Ki67 $>3 \%$ associated with an odds ratio of 18.2 (2.54-13) with $p<$ 0.005. Ki67 was a predictor of liver metastases with an odds ratio of 6.79 (1.56-29.5) with $p<0.05$ in the multivariate analysis. Size was a key predictor of both lymph node and liver metastases. Lesions that were between 11 and $20 \mathrm{~mm}$ in size in size had an odds ratio of $11.1(1.16-106)$ compared to lesions $<11 \mathrm{~mm}$ for the presence of lymph node metastases in the multivariate analysis $(p<0.05)$. When lesions $>$ $20 \mathrm{~mm}$ were compare to lesions $<11 \mathrm{~mm}$, the odds ratio was $16.7(2.08-134)(1.4-$ 33.86) with $p<0.01$ ) for prediction of liver metastases in the multi-variate. The only non-functioning dNEN that had lymph node metastases had a Ki67 of $10 \%$. 
To identify the optimal cut-off for the prediction of lymph node metastases ROC (receiver operating characteristic) analysis was performed for dNENs that were of low grade and non-functioning. Lesions less than $15 \mathrm{~mm}$ had an AUROC of 0.9 (0.81-0.99) with a sensitivity of $85 \%$ and specificity of $88 \%$ for the prediction of lymph node metastases (Figure 2)

\section{Discussion}

Overall dNENs have an excellent prognosis. Our finding of only 4 deaths with disease related mortality is similar to previous retrospective studies that have demonstrated an overall 5-year survival for all dNENs has been reported at $85 \%$ with median overall survival of 187 months $[8,15]$. The 5 year survival for lesions less than $1 \mathrm{~cm}$ in size was $100 \%$ in our study.

This study has further demonstrated the changing spectrum of dNENs. There were $87 / 102(85 \%)$ non-functioning dNENs, compared to $106 / 166(63.6 \%)$ in an earlier retrospective study by Vanoli et al16]. A more recent retrospective series by Massironi et al found 78/108 (72\%) were non-functioning [8].

The largest published data on dNENs looked at 1,258 identified from SEER found an increasing proportion of patients found at an earlier stage (Stage I-II) increased from $65 \% 1983-2005$, to $79 \%$ in $2006-2010$ [17]. This was mirrored in our study as $71 \%$ of patients were found between Stage I-II.

Current ENETS guidelines recommend endoscopic removal for all lesions that are $<10 \mathrm{~mm}$ in size and surgery for all lesions that are $>20 \mathrm{~mm}$ in size, T2 or if there is incomplete resection. For lesions between $10-20 \mathrm{~mm}$ without nodal spread there was no overall consensus as either endoscopy or surgery could be considered in these 
patients [14]. The guidelines do emphasise the need for careful staging with both EUS and cross-sectional imaging prior to any attempts at endoscopic resection.

Endoscopic resection was performed in 17 patients with 8 patients having an incomplete $\mathrm{R} 1$ resection, and two patients suffering a perforation and requiring emergency surgery. There were no clear predictors with regard to size or location that could predict an incomplete resection or a perforation. A retrospective study of 38 dNENs measuring $<10 \mathrm{~mm}$ by Kim et al found $17 / 38$ patients $(41 \%)$ had a clear histopathological resection margin. The four cases that underwent endoscopic submucosal resection (ESD) all had a clear resection margin [13]. The duodenum is thin walled and has a narrow lumen making endoscopic resection more challenging and associated with significant risk of perforation and bleeding [18]. ESD is associated with far greater risk than in the lower Gl tact and perforation has been reported in up to $30 \%$ of cases in the duodenum [12].

In our case series, 36 patients that could have been considered for ER or surgical resection were placed on active surveillance alone. They underwent annual endoscopic surveillance and cross sectional imaging. There was no progression seen in these patients and 5 year survival was 100\%. The prognosis for nonfunctioning dNENs without local or distant metastases is very good. The relatively high complication rate and incomplete resection with $\mathrm{ER}$, and the worse quality of life reported after surgical resection [11], it may be lesions that show such indolent behaviour are best kept on surveillance alone.

To help identify which lesions could be considered for observation alone we looked at looked factors that could be predictive of lymph node and liver metastases in nonfunctioning dNENs. In the logistic regression analysis, Ki67 >3\% and size $>2 \mathrm{~cm}$ 
were the strongest predictors of lymph nodes metastases. In ROC analysis of G1 non-functioning dNENs a cut-off of $<15 \mathrm{~mm}$ in size had an AUROC of 0.96 with a sensitivity of $92 \%$ and specificity of $89 \%$. A study by Park et al that analysed 44 dNENs all removed at endoscopy in 38 patients found size $>10 \mathrm{~mm}$, non-bulbar location, invasion beyond sub-mucosa (found at EUS) and lymphovascular invasion were predictors of LN metastases [19]. Vanoli et al found similar findings with regard grade, submucosal penetration and grade. In their ROC analysis they found a cut-off of $0.9 \mathrm{~cm}$ had an AUROC of 0.79 , with sensitivity of $84 \%$ and specificity of $73 \%$, however they included G2 dNENs in their analysis [16].This study has a number of limitations due to its retrospective nature looking at outcome and treatments across 3 different centres with varying approaches to in particular endoscopic management. As dNENs are often slow growing, there were very few deaths therefore the survival data has to be interpreted with caution. There was also data missing from findings at endoscopic ultrasound.

It was difficult to determine progression as a surrogate end point as currently there is no definition of what would be deemed endoscopic progression for dNENs that were being kept under surveillance without any radiologically measurable disease.

Nevertheless, the findings of this study concur with recent publications documenting the rise in incidence of non-functioning dNENs, their good prognosis and the risk factors associated with more aggressive disease. There is a cohort of patients that could be considered for active surveillance alone but this needs further evaluation in large, long-term multi-centre prospective settings. .

In conclusion, although dNENs appear to be increasing in incidence, this seems to be primarily made up of non-functioning dNENs which are associated with a very 
good prognosis. The role of endoscopic resection for dNEN that are associated with good outcome, (low grade, non-functioning and less than $11 \mathrm{~mm}$ in size) needs to be reviewed. From our experience across three ENETS centre of excellence we have developed an algorithm for the management of non-functioning dNENs which could prevent unnecessary intervention associated with significant morbidity but also ensure adequate surveillance still takes place where indicated( Figure 3).

\section{$\underline{\text { References }}$}

1/Delle Fave G, Kwekkeboom DJ, Van Cutsem E, et al. ENETS consensus guidelines for the management of patients with gastroduodenal neoplasms. Neuroendocrinology 2012;95:74-87. doi:10.1159/000335595

2/ Modlin IM, Lye KD, Kidd M. A 5-decade analysis of 13,715 carcinoid tumors. Cancer 2003;97:934-59. doi:10.1002/cncr.11105

3/Dasari $\mathrm{A}^{1}$, Shen $\mathrm{C}^{2,3}$, Halperin $\mathrm{D}^{1}$, et al Trends in the Incidence, Prevalence, and Survival Outcomes in Patients With Neuroendocrine Tumors in the United States. JAMA Oncol. 2017 Oct 1;3(10):13351342. doi: 10.1001/jamaoncol.2017.0589.

4/ Hallet J, Law CHL, Cukier M, et al. Exploring the rising incidence of neuroendocrine tumors: A population-based analysis of epidemiology, metastatic presentation, and outcomes. Cancer 2015;121:589-97. doi:10.1002/cncr.29099

5/ Hoffmann KM, Furukawa M, Jensen RT. Duodenal neuroendocrine tumors: Classification, functional syndromes, diagnosis and medical treatment. Best Pract Res Clin Gastroenterol 2005;19:675-97. doi:10.1016/j.bpg.2005.05.009

6/ Klöppel G, Perren A, Heitz PU. The gastroenteropancreatic neuroendocrine cell system and its tumors: The WHO classification. Ann N Y Acad Sci 2004;1014:13-27. doi:10.1196/annals.1294.002

7/ Heymann MF, Hamy A, Triau S, et al. Endocrine tumors of the duodenum. A study of 55 cases relative to clinicopathological features and hormone content. Hepatogastroenterology 2004;51:136771.

8/Massironi S, Campana D, Partelli S, et al. Heterogeneity of Duodenal Neuroendocrine Tumors: An Italian Multi-center Experience. Ann Surg Oncol 2018;:6-8. doi:10.1245/s10434-018-6673-5 
9/ Bornstein-Quevedo L, Gamboa-Domnguez A. Carcinoid tumors of the duodenum and ampulla of vater: A clinicomorphologic, immunohistochemical, and cell kinetic comparison. Hum Pathol 2001;32:1252-6. doi:10.1053/hupa.2001.28955

10/ Nassar H, Albores-Saavedra J, Klimstra DS. High-grade neuroendocrine carcinoma of the ampulla of vater: A clinicopathologic and immunohistochemical analysis of 14 cases. Am J Surg Pathol 2005;29:588-94. doi:10.1097/01.pas.0000157974.05397.4f

11/Dogeas E, Cameron JL, Wolfgang CL, et al Duodenal and Ampullary Carcinoid Tumors: Size Predicts Necessity for Lymphadenectomy J Gastrointest Surg. 2017 Aug;21(8):12621269. doi: 10.1007/s11605-017-3448-4. Epub 2017 May 17.

12; Exarchou K, Howes N, Pritchard DM. Systematic review: management of localised lowgrade upper gastrointestinal neuroendocrine tumours

Aliment Pharmacol Ther. 2020 Jun;51(12):1247-1267. doi: 10.1111/apt.15765. Epub 2020 May 11

13/ Kim GH, Kim JI, Jeon SW, et al; Endoscopic resection for duodenal carcinoid tumors: a multicenter, retrospective study Korean College of Helicobacter and Upper Gastrointestinal Research. J Gastroenterol Hepatol. 2014;29:318-24.

14/ Delle Fave G, O'Toole D,et al; Vienna Consensus Conference participants.ENETS Consensus Guidelines Update for Gastroduodenal Neuroendocrine Neoplasms. Neuroendocrinology. 2016;103(2):119-24. doi: 10.1159/000443168.

15/ Soga J. Endocrinocarcinomas (carcinoids and their variants) of the duodenum. An evaluation of 927 cases. J Exp Clin Cancer Res 2003;22:349—363.http://europepmc.org/abstract/MED/14582691

16/ Vanoli A ${ }^{1}$, La Rosa S, Klersy C, et al. Four Neuroendocrine Tumor Types and Neuroendocrine Carcinoma of the Duodenum: Analysis of 203 Cases. Neuroendocrinology 2017;104:112-125 DOI: $10.1159 / 000444803$

17/Fitzgerald TL, Dennis SO, Swapnil . Increasing incidence of duodenal neuroendocrine tumors: Incidental discovery of indolent disease? Surgery Volume 158, Number 2

18/ Inoue T, Uedo N, Yamashina Tet al. Delayed perforation: a hazardous complication of endoscopic resection for non-ampullary duodenal neoplasm. Dig Endosc. 2014 Mar;26(2):220-7. doi:

10.1111/den.12104. Epub 2013 Apr 29

19/ Park SG, Lee BE, Kim GH,et al. Risk factors for lymph node metastasis in duodenal neuroendocrine tumors: A retrospective, single-center study.

Medicine (Baltimore). 2019 Jun;98(23):e15885. doi: 10.1097/MD.0000000000015885

20/ Bauder M, Schmidt A, Caca K. Endoscopic full-thickness resection of duodenal lesions-a retrospective analysis of 20 FTRD cases. Bauder M, Schmidt A, Caca K. United European Gastroenterol J. 2018 Aug;6(7):1015-1021. doi: 10.1177/2050640618773517. Epub 2018 May 12 


\section{Tables}

\begin{tabular}{|c|c|}
\hline Number of patients & $10257 \mathrm{~m} / 45 \mathrm{f}$ \\
\hline Mean age at diagnosis & $62(32-87)$ \\
\hline Location D1 & $63(62 \%)$ \\
\hline D2 & $19(19 \%)$ \\
\hline D3 & $3(3 \%)$ \\
\hline D4 & $2(2 \%)$ \\
\hline Unknown & $15(15 \%)$ \\
\hline Grade $1 \mathrm{Ki} 67<3 \%$ & $68(67 \%)$ \\
\hline Grade 2 Ki 67 (3-20\%) & $21(21 \%)$ \\
\hline Grade $3 \mathrm{Ki} 67>20 \%$ & $3(3 \%)$ \\
\hline Unknown & $10(10 \%)$ \\
\hline Size & Mean $16 \mathrm{~mm}$ (range $0.9-130 \mathrm{~mm})$ \\
\hline & Median 10mm \\
\hline$<10 \mathrm{~mm}$ & $43(42 \%)$ \\
\hline $11-20 \mathrm{~mm}$ & $39(38 \%)$ \\
\hline$>20 \mathrm{~mm}$ & $18(18 \%)$ \\
\hline Unknown & $2(2 \%)$ \\
\hline Subtype - Non-functioning & $87(85 \%)$ \\
\hline Gastrinoma & $9(9 \%)$ \\
\hline Carcinoid & $3(3 \%)$ \\
\hline Paraganglioma & $1(1 \%)$ \\
\hline Poorly differentiated NEC & 2 \\
\hline Stage I & $48(47 \%)$ \\
\hline Stage II & $21(21 \%)$ \\
\hline Stage III & $8(8 \%)$ \\
\hline Stage IV & $25(25 \%)$ \\
\hline Non-medical treatment & 83 patients \\
\hline Active surveillance & $36(43 \%)$ \\
\hline Endoscopic resection & $17(20 \%)$ \\
\hline Surgery & 30(36\%) PPPD 4 \\
\hline & Whipples 8 \\
\hline & Segmental resection 9 \\
\hline & Partial duodenectomy 9 \\
\hline & Synchronous liver mets resection $8 \mathrm{pts}$ \\
\hline Medical treatment & 25 patients \\
\hline SSTA's & $23(92 \%)$ \\
\hline Chemotherapy & $7 \quad(28 \%)$ \\
\hline PRRT & $5(20 \%)$ \\
\hline Functional imaging avidity & \\
\hline Gallium PET scan & $31 / 55(56 \%)$ \\
\hline FDG avidity & $8 / 39(21 \%)$ \\
\hline
\end{tabular}

Table 1. Demographics and clinical characteristics of 102 dNENs. PPPD -pylorus preserving pancreatoduodenectomy. SSTA - somatostatin analogues. PRRT - peptide radiolabelled receptor targeted therapy. 


\begin{tabular}{|l|l|l|l|l|}
\hline Characteristic & Univariate HR & $\begin{array}{l}\text { Univariate } \\
\mathrm{p}\end{array}$ & Multivariate HR & $\begin{array}{l}\text { Multivariate } \\
\mathrm{p}\end{array}$ \\
\hline Age & $2.62[1.51-4.54]$ & $\mathrm{p}=0.0006$ & $1.96[0.97-3.96]$ & $\mathrm{p}=0.061$ \\
\hline $\begin{array}{l}\text { Gender } \\
\text { Female } \\
\text { Male }\end{array}$ & 1 & & & \\
\hline $\begin{array}{l}\text { Size } \\
\text { <=10mm }\end{array}$ & $1.62[0.49-5.38]$ & $\mathrm{p}=0.434$ & & \\
$\begin{array}{l}\text { 11-20mm } \\
>\text { 20mm }\end{array}$ & $1.34[0.37-4.80]$ & $\mathrm{p}=0.654$ & & \\
\hline $\begin{array}{l}\text { Location } \\
\text { D1 }\end{array}$ & $1.09[0.21-5.54]$ & $\mathrm{p}=0.916$ & & \\
D2 & 1 & & & \\
\hline $\begin{array}{l}\text { Ki67 } \\
\text { G1-2 } \\
\text { G3 }\end{array}$ & $1.23[0.31-4.93]$ & $\mathrm{p}=0.772$ & & \\
\hline $\begin{array}{l}\text { FDG } \\
\text { Negative }\end{array}$ & 1 & & 1 & \\
Positive & $12.5[2.38-65.2]$ & $\mathrm{p}=0.003$ & $5.10[0.79-32.8]$ & $\mathrm{p}=0.086$ \\
\hline $\begin{array}{l}\text { 68Ga } \\
\text { Negative }\end{array}$ & $1.44[0.15-14.2]$ & $\mathrm{p}=0.753$ & & \\
Positive & 1 & & & \\
\hline $\begin{array}{l}\text { Functional } \\
\text { Non-functional }\end{array}$ & 1 & & & \\
Functional & $3.32[0.98-11.2]$ & $\mathrm{p}=0.053$ & $2.19[0.52-9.14]$ & $\mathrm{p}=0.284$ \\
\hline $\begin{array}{l}\text { Liver mets* } \\
\text { Absent }\end{array}$ & 1 & & & \\
Present & $2.87[0.92-9.00]$ & $\mathrm{p}=0.071$ & $2.16[0.67-6.97]$ & $\mathrm{p}=0.196$ \\
\hline $\begin{array}{l}\text { LN mets } \\
\text { Absent } \\
\text { Present }\end{array}$ & $1.99[0.63-6.29]$ & $\mathrm{p}=0.239$ & & \\
\hline
\end{tabular}

Table 2 Cox-hazards ratio for univariate and multi-variate analysis for OS for dNENs. *Colinear with Ki67 so calculated in separate multivariate model. See supplementary data. 


\begin{tabular}{|c|c|c|c|c|}
\hline Characteristic & Univariate OR & Univariate $\mathrm{p}$ & Multivariate OR & Multivariate $\mathrm{p}$ \\
\hline $\begin{array}{l}\text { Age } \\
\text { In tens }\end{array}$ & $1.03[0.71-1.50]$ & $\mathrm{p}=0.876$ & & \\
\hline $\begin{array}{l}\text { Gender } \\
\text { Female } \\
\text { Male } \\
\end{array}$ & $\begin{array}{l}1 \\
0.33[0.12-0.87]\end{array}$ & $\mathrm{p}=0.025$ & $\begin{array}{l}1 \\
0.05[0.005-0.52]\end{array}$ & $p=0.012$ \\
\hline $\begin{array}{l}\text { Size } \\
\quad<=10 \mathrm{~mm} \\
11-20 \mathrm{~mm} \\
>20 \mathrm{~mm} \\
\end{array}$ & $\begin{array}{l}1 \\
7.35[1.40-38.6] \\
91[13.7-605] \\
\end{array}$ & $\begin{array}{l}\mathrm{p}=0.018 \\
\mathrm{p}<0.00001\end{array}$ & $\begin{array}{l}1 \\
11.1[1.16-106] \\
457[17.4-11986]\end{array}$ & $\begin{array}{l}p=0.037 \\
p=0.0002\end{array}$ \\
\hline $\begin{array}{l}\text { Location* } \\
\text { D1 } \\
\text { D2 }\end{array}$ & $\begin{array}{l}1 \\
4.76[1.30-17.5]\end{array}$ & $\mathrm{p}=0.019$ & $\begin{array}{l}1 \\
8.58[1.26-58.6]\end{array}$ & $p=0.028$ \\
\hline $\begin{array}{l}\text { Grade } \\
\text { G1 } \\
\text { G2-3 }\end{array}$ & $\begin{array}{l}1 \\
19.7[5.38-72.1]\end{array}$ & $\mathrm{P}<0.00001$ & $\begin{array}{l}1 \\
18.2[2.54-131]\end{array}$ & $p=0.004$ \\
\hline $\begin{array}{l}\text { FDG** } \\
\text { Negative } \\
\text { Positive }\end{array}$ & $\begin{array}{l}1 \\
9.2[1.30-64.9]\end{array}$ & $\mathrm{p}=0.026$ & $\begin{array}{l}1 \\
9.23[1.28-66.8]\end{array}$ & $p=0.028$ \\
\hline $\begin{array}{l}68 \mathrm{Ga} \\
\text { Negative } \\
\text { Positive } \\
\end{array}$ & $\begin{array}{l}1 \\
2.71[0.68-10.8]\end{array}$ & $\mathrm{p}=0.158$ & & \\
\hline
\end{tabular}

Table 3. Summary of univariate and multi-variate cause logistic regression for all nonfunctioning dNENs to predict LN metastases. *Location was multi co-linear with FDG and size, so was analysed in a separate multivariate model - please see supplementary tables. **FDG was multi co-linear with grade, location and size, so was analysed in a separate multivariate model - please see supplementary tables 


\begin{tabular}{|l|l|l|l|l|}
\hline Characteristic & Univariate OR & Univariate $\mathrm{p}$ & Multivariate OR & Multivariate $\mathrm{p}$ \\
\hline $\begin{array}{l}\text { Age } \\
\text { In tens }\end{array}$ & $1.05[0.70-1.57]$ & $\mathrm{p}=0.829$ & & \\
\hline $\begin{array}{l}\text { Gender } \\
\text { Female } \\
\text { Male }\end{array}$ & 1 & & & \\
\hline $\begin{array}{l}\text { Size } \\
\quad=10 \mathrm{~mm}\end{array}$ & 1 & & 1 & \\
$\begin{array}{l}\text { 11-20mm } \\
>20 \mathrm{~mm}\end{array}$ & $5.86[1.09-31.6]$ & $\mathrm{p}=0.040$ & $5.16[0.76-35.2]$ & $\mathrm{p}=0.093$ \\
\hline $\begin{array}{l}\text { Location* } \\
\text { D1 }\end{array}$ & $26.4[4.68-149]$ & $\mathrm{p}=0.00003$ & $16.7[2.08-134]$ & $\mathbf{p}=\mathbf{0 . 0 0 8}$ \\
D2 & 1 & & & \\
\hline Grade & $8.67[2.02-36.9]$ & $\mathrm{p}=0.004$ & $23.0[2.26-234]$ & $\mathbf{p}=\mathbf{0 . 0 0 8}$ \\
$\quad$ G1 & 1 & & & \\
G2-3 & $16.2[4.50-58.3]$ & $\mathrm{p}=0.00002$ & $6.79[1.56-29.5]$ & $\mathbf{p}=\mathbf{0 . 0 1 1}$ \\
\hline FDG** & 1 & & & \\
Negative & $6.00[0.88-40.9]$ & $\mathrm{p}=0.067$ & $6.09[0.89-41.9]$ & $\mathrm{p}=0.066$ \\
Positive & 1 & & & \\
\hline 68Ga & $1.40[0.32-6.07]$ & $\mathrm{p}=0.655$ & & \\
Negative & & & & \\
Positive & & & & \\
\hline
\end{tabular}

Table 4. Summary of univariate and multi-variate analysis for all non-functioning dNENS to predict liver metastases. *Location was multi-collinear with FDG and size, so was analysed in a separate multivariate model - please see supplementary tables. **FDG was multi-collinear with grade, location and size, so was analysed in a separate multivariate model - please see supplementary tables 
Figures

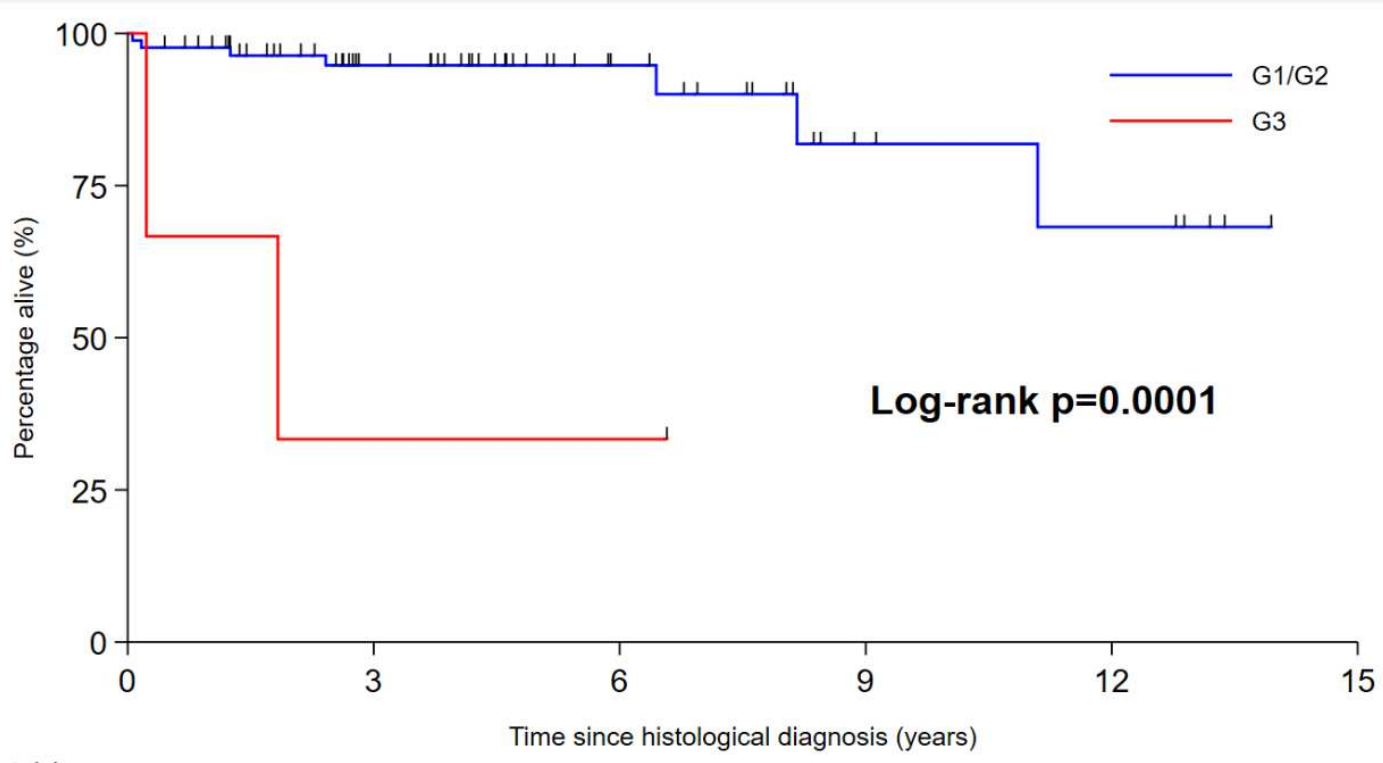

Number at risk

G1/G2 $\quad 86$

48

G3 3

1

5

0

3

0

Figure 1: Kaplan-Meier survival curve for dNENs using a Ki67 cut-off of $20 \%$ (G3).

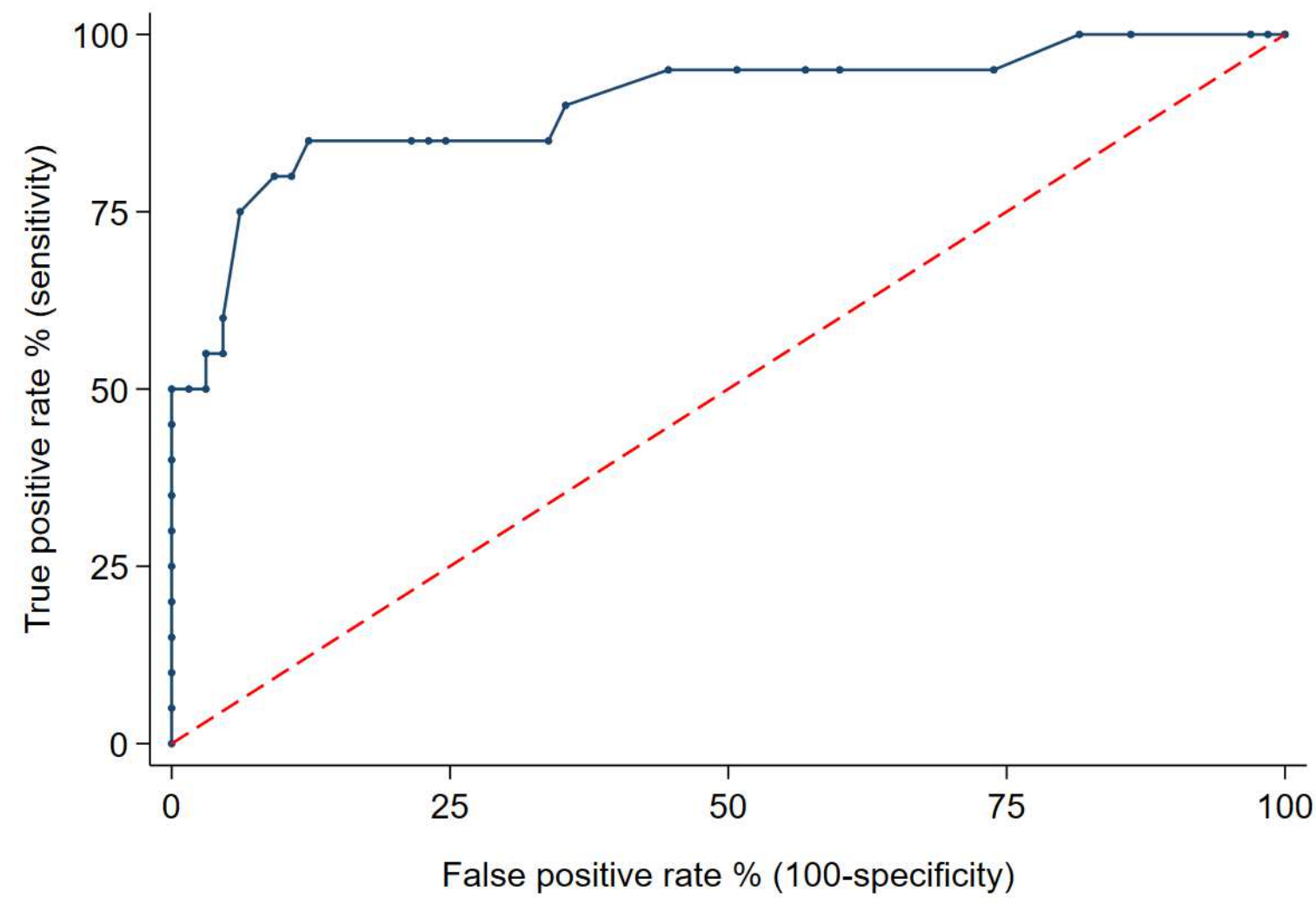


Figure 2. AUROC analysis for size of dNENs as a predictor of LN metastases in non-functioning $d$ NENs. 


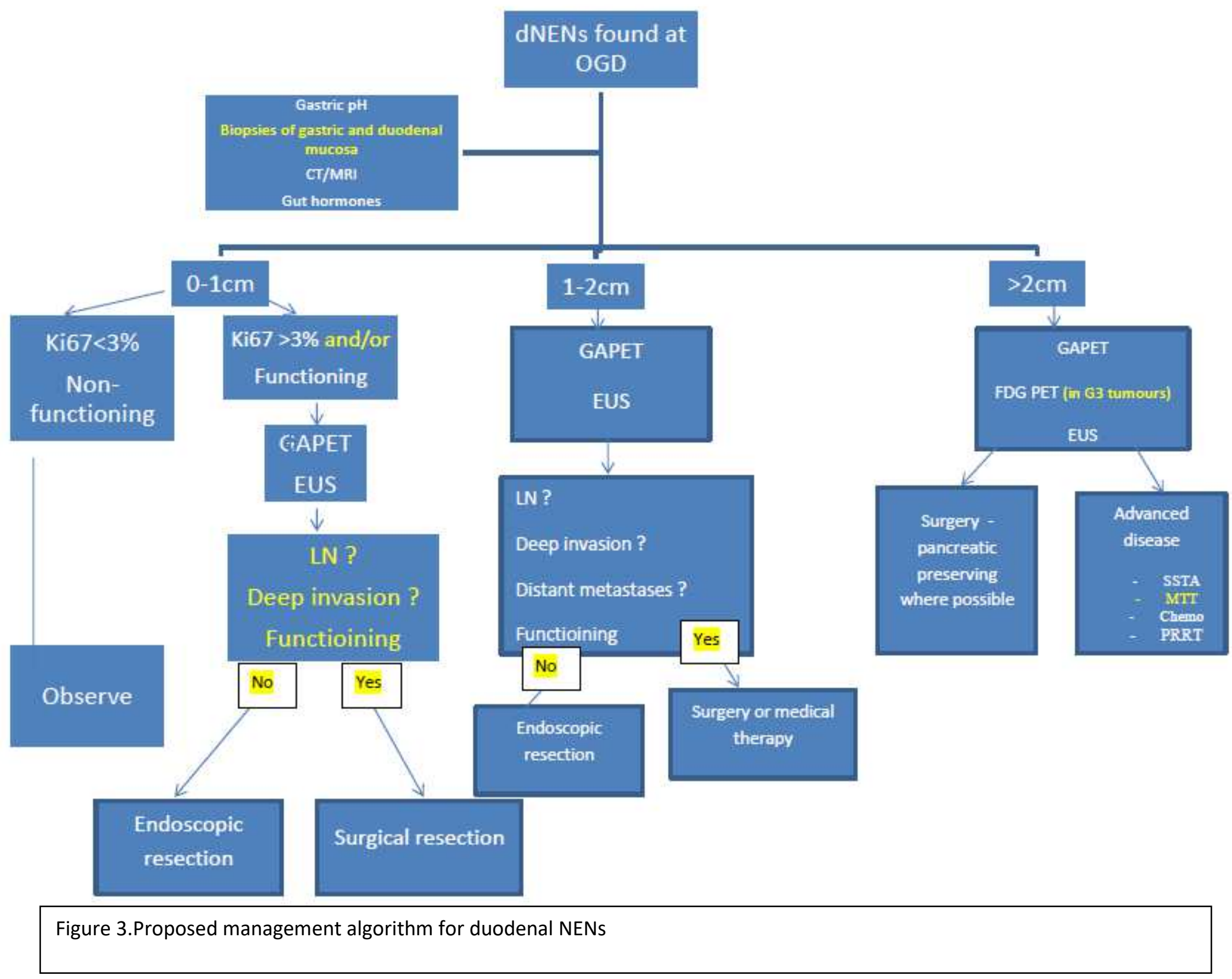




\section{Supplementary Files}

This is a list of supplementary files associated with this preprint. Click to download.

- Supplementarytables.docx 